\title{
Biparental expression of ESX1L gene in placentas from normal and intrauterine growth-restricted pregnancies
}

\author{
Francesca R Grati ${ }^{1}$, Silvia M Sirchia ${ }^{1}$, Barbara Gentilin ${ }^{1}$, Franca Rossella ${ }^{1}$, \\ Lisetta Ramoscelli ${ }^{1}$, Patrizio Antonazzo ${ }^{2}$, Ugo Cavallari ${ }^{1}$, Gaetano Bulfamante ${ }^{3}$, \\ Irene Cetin ${ }^{2}$, Giuseppe Simoni ${ }^{1}$ and Monica Miozzo*,1 \\ ${ }^{1}$ Genetica Medica, Dipartimento di Medicina, Chirurgia ed Odontoiatria, Università di Milano, Milano, Italy; ${ }^{2}$ Clinica \\ Ostetrica e Ginecologica, Dipartimento di Medicina, Chirurgia ed Odontoiatria, Ospedale San Paolo, Università di \\ Milano, Milano, Italy; ${ }^{3}$ Anatomia Patologica, Dipartimento di Medicina, Chirurgia ed Odontoiatria, Ospedale San \\ Paolo, Università di Milano, Milano, Italy
}

Equivalent levels of $X$-linked gene products between males and females are reached by means of $X$ chromosome inactivation $(\mathrm{XCl})$. In the human and murine embryonic tissues, both the paternally and maternally derived $X$ chromosomes $\left(X^{P}\right.$ and $X^{M}$ ) may be inactivated. In murine extra-embryonic tissues, $X^{P}$ is imprinted and always silenced; humans, unlike mice, can inactivate the $X^{M}$ in extra-embryonic lineages without an adverse outcome. This difference is probably due to the presence of imprinted placental genes on the murine $X$ chromosome, but not on the human homologue, essential for placental development and function. An example is the paternally imprinted $E s \times 1$ gene; mice with a null maternally derived Esx 1 allele show intrauterine growth restriction (IUGR) because of placental insufficiency. We investigated the imprinting status of the human orthologous $E s \times 1$ gene (ESX1L) in placental samples of four normal full-term and 13 IUGR female fetuses, in which we determined the $\mathrm{XCI}$ pattern. Our findings demonstrated that IUGR as well as normal placentas display $\mathrm{XCI}$ heterogeneity, thus indicating that the IUGR phenotype is not correlated with a preferential pattern of $\mathrm{XCl}$ in placentas. Moreover, ESX1L is equally expressed in IUGR and normal placentas, and shows the same methylation pattern in the presence of both random and skewed $\mathrm{XCl}$. These findings provide evidence that ESX1L is not imprinted in human third-trimester placentas and there is no parent-of-origin effect of chromosome $X$ associated with placental insufficiency.

European Journal of Human Genetics (2004) 12, 272-278. doi:10.1038/sj.ejhg.5201121

Published online 3 December 2003

Keywords: X chromosome inactivation; ESX1L imprinting; IUGR

\section{Introduction}

$\mathrm{X}$ chromosome inactivation (XCI) is the mechanism that ensures equivalent levels of $\mathrm{X}$ chromosome gene products

*Correspondence: Dr M Miozzo, Laboratorio di Genetica Medica, Blocco C, 5 Piano, Dipartimento di Medicina Chirurgia e Odontoiatria, Università degli studi di Milano Via di Rudinì 8, 20142 Milano MI, Italy.

Tel: + 3902 89179245; Fax: + 3902 89179246;

E-mail: monica.miozzo@unimi.it

Received 4 June 2003; revised 2 September 2003; accepted 9 September 2003 in males and females by silencing most of the genes on the inactivated $\mathrm{X}$ chromosome. ${ }^{1,2}$ It occurs early, from the late morula to the blastocyst stage, ${ }^{3}$ and is generally stable through subsequent cell divisions.

In the embryonic tissues of murine and human females, $\mathrm{X}$ inactivation is usually random, with an equal probability of the maternally or paternally derived $\mathrm{X}$ chromosome $\left(\mathrm{X}^{\mathrm{M}}, \mathrm{X}^{\mathrm{P}}\right)$ being inactivated in a given cell. Preferential $\mathrm{XCI}$ is an infrequent event in humans, which can be associated with conditions such as extensive $\mathrm{X}$ 
chromosome structural rearrangements, X-linked lethal traits and reduction of the number of embryonic precursor cells in the inner mass at the time of XCI commitment. ${ }^{4,5}$ In extra-embryonic tissues of marsupials and mice, the $\mathrm{X}^{\mathrm{P}}$ is always inactivated. ${ }^{3}$ In humans, conflicting data have been reported; of four recent studies, using the methylation assay of androgen receptor $(A R)$, one reported $\mathrm{X}^{\mathrm{P}}$ preferential inactivation, ${ }^{6}$ and three showed both random and preferential XCI. ${ }^{7-9}$ In particular, Looijenga et $\mathrm{al}^{7}$ demonstrated a heterogeneous (random and preferential) $\mathrm{XCI}$ pattern even in different sites of the placental unit.

In mouse, $X^{M}$ is resistant to inactivation in extraembryonic tissues. ${ }^{10,11}$ For this reason, embryos with an extra $\mathrm{X}^{\mathrm{M}}$ chromosome display an almost complete absence of placental tissue, probably because of an anomalous expression of the murine $\mathrm{X}$-linked genes involved in placental development. ${ }^{12-14}$ Moreover, the embryonic death of conceptuses that are disomic for $\mathrm{X}^{\mathrm{M}}$ chromosome results from a failure to undergo $X$ inactivation in extraembryonic tissues. ${ }^{15}$ In humans, supernumerary $\mathrm{X}$ chromosomes of either maternal or paternal origin do not represent lethal conditions because $\mathrm{X}^{\mathrm{M}}$ can be inactivated in extra-embryonic tissues without any adverse outcome on pregnancy.

Intrauterine growth restriction (IUGR) is a condition of pregnancy characterized by fetal growth reduction and placenta insufficiency. ${ }^{16}$ A number of fetal (chromosomal abnormalities, confined placental mosaicism, congenital malformations, infection) and maternal causes (malnutrition, vascular/renal disease, congenital or acquired thrombophilic disorder, drugs/lifestyle) have been associated with IUGR. ${ }^{17}$ However, in most cases, no specific cause can be identified and the placenta does not develop adequately due to an incorrect invasion of maternal arteries by the trophoblast. Several evidences indicate that IUGR may be associated with altered levels of autosomal imprinted gene expression. ${ }^{18-20}$ Most of the imprinted genes involved in fetal/placental growth have been discovered in murine models, including Esx1, an imprinted X-linked gene that is maternally expressed. ${ }^{21} \mathrm{Li}$ and Behringer $^{22}$ reported that mice with Esx 1 deletion affecting the maternally derived allele are $20 \%$ smaller with respect to controls and show placental insufficiency; these authors and Looijenga et $\mathrm{al}^{7}$ suggested a relationship between Esx1 and human IUGR. No data are available concerning the role of the human orthologous $E S X 1 L^{23}$ and its effect on human pregnancy but, in the case of a similar ESX1L imprinting status to that in mouse, preferential $\mathrm{X}^{\mathrm{M}}$ inactivation in placental tissue could inactivate the expressed allele and have an adverse effect on placental function.

We studied the XCI pattern and the imprinting status of the ESX1L gene in placental tissues from idiopathic female IUGR pregnancies to investigate the role of chromosome $\mathrm{X}$ imprinting in human pregnancy.

\section{Material and methods \\ Patients}

Pregnant women were recruited in the Unit of Obstetrics and Gynecology of the San Paolo Hospital of Milan. The protocol was approved by the Local Ethics Committee, and informed consent was obtained from both parents.

We studied 13 pregnancies carrying an IUGR female fetus at the time of elective cesarean section performed at 26-37 weeks of gestation. The IUGR fetuses were identified in utero by means of serial ultrasound examinations: their abdominal circumference measurements were less than the 10th percentile of the age-related reference values, and they showed a decrease of more than 40 percentiles from the growth standard curve. ${ }^{24}$ Growth restriction at birth was confirmed if the neonatal weight was less than the 10th percentile of the Italian standards for birth weight and gestational age. ${ }^{25}$ The exclusion criteria were any maternal condition known to be associated with IUGR, such as smoking, alcohol consumption and poor nutrition, maternal diseases, such as autoimmune diseases, thrombophilia and diabetes, abnormalities of the placenta and fetal malformations. The cesarean sections were performed in the interests of the fetus as part of our routine clinical protocol. ${ }^{26}$ The severity of IUGR was evaluated by means of a Doppler velocimetry assessment of the fetal umbilical artery (pulsatility index: PI) and fetal heart rate (FHR) recordings performed immediately before cesarean section. On the basis of the PI measurements and FHR patterns, the fetuses were divided into the following four IUGR subgroups as previously described ${ }^{26}$ : Group 1: normal FHR and PI; Group 2: normal FHR, abnormal PI; Group 3: abnormal FHR and PI; Group 4: abnormal FHR tracing and normal PI.

A control group of four normal full-term (two males and two females) pregnancies was also studied. These were noncomplicated pregnancies, with normal intrauterine growth determined in utero by routine ultrasound and confirmed at birth according to Italian standards for birth weight and gestational age. ${ }^{25}$ The clinical data pertaining to the studied patients are shown in Table 1.

\section{Tissue collection}

At the time of delivery, we collected for each case 2-4 full-thickness placental samples (A-D) taken from different cotyledons, umbilical cord fragment (UC) and/ or cord blood sample (CB). One-half of each placental specimen was formalin fixed and paraffin embedded for the diagnostic histologic evaluation. The degree of ramification and maturation of the villous tree was classified using the method proposed by Benirshke and Kaufmann. ${ }^{27}$ After washing with PBS to eliminate residual blood, the placental samples were minced and microscopically inspected in order to remove any contaminating fragments 
Table 1 Clinical data of IUGR (cases 3-40) and normal pregnancies (cases 52-60)

\begin{tabular}{|c|c|c|c|c|c|c|}
\hline CASE & Gestational age & $B W(g)$ & Percentile & $P W(g)$ & $B W / P W$ & IUGR severity \\
\hline 3 & 32.0 & 1000 & 10th & 156 & 6.4 & 2 \\
\hline 8 & 31.0 & 1220 & 5 th & 141 & 8.7 & 3 \\
\hline 9 & 35.0 & 1590 & $<5$ th & 400 & 4.0 & 2 \\
\hline 12 & 32.6 & 1550 & 5 th & 150 & 10.3 & 2 \\
\hline 13 & 29.6 & 451 & $<5$ th & 310 & 1.5 & 3 \\
\hline 15 & 32.0 & 1100 & 10th & 145 & 7.6 & 3 \\
\hline 20 & 37.0 & 2340 & $5-10$ th & 318 & 7.4 & 2 \\
\hline 30 & 26.2 & 490 & $<5$ th & 96 & 5.1 & 3 \\
\hline 33 & 37.2 & 1960 & $<5$ th & 336 & 5.8 & 2 \\
\hline 35 & 36.1 & 2000 & $5-10$ th & 328 & 6.1 & 4 \\
\hline 36 & 35.5 & 2000 & $5-10$ th & 331 & 6.0 & 2 \\
\hline 37 & 33.1 & 1250 & $5-10$ th & 151 & 8.3 & 1 \\
\hline 40 & 37.3 & 1920 & $<5$ th & 274 & 7.0 & 1 \\
\hline 52 & 39.2 & 3020 & $10-50$ th & 495 & 6.1 & 1 \\
\hline 55 & 40.5 & 2990 & $10-50$ th & 420 & 7.1 & / \\
\hline 56 & 39.2 & 2970 & $10-50$ th & 431.5 & 6.9 & / \\
\hline 60 & 40.2 & 3600 & $50-90$ th & 487 & 7.4 & / \\
\hline
\end{tabular}

$\mathrm{BW}=$ birth weight; $\mathrm{PW}=$ placental weight.

of maternal decidua. The selected amount of chorionic villi was divided into three aliquots for cell cultures, DNA and RNA extractions. Parent's DNAs were obtained from peripheral blood lymphocytes (PBL). Placental fragments from the four normal pregnancies were analyzed for evaluation of ESX1L expression and methylation status.

\section{Cytogenetic analysis}

The chorionic villi were cultured using standard procedures, and chromosome spreads from stromal cells were obtained within 2 weeks. Chromosome preparations from CB samples were harvested after $72 \mathrm{~h}$ of culture in Chromosome Medium P (EuroClone, Wetherby, West Yorkshire, UK). Chromosomes were Q-banded and at least 15 metaphases were karyotyped for each sample.

\section{$\mathrm{X}$ chromosome inactivation assay}

DNAs were extracted from fetal/placental samples and parental PBL using standard procedures. XCI was assayed on fetal-placental DNAs of all cases and mother's PBL of cases 33 and 35.

The XCI assay is based on the methylation-sensitive HpaII restriction site located in the polymorphic region (CAG repeats) of the androgen receptor gene $(A R, \mathrm{Xq} 12)$, which is methylated on the inactive and unmethylated on the active $\mathrm{X}$ chromosome. When HpaII is used to digest genomic DNA before PCR, the $A R$ allele is amplified only from the inactive $X$ chromosome because the specific sequence on the active $\mathrm{X}$ chromosome is cleaved by the restriction enzyme. Genomic DNA enzymatic digestion, PCR conditions and specific primers have been previously described by Allen et al. ${ }^{28}$ An undigested DNA and a male
DNA were included in each experiment as controls. For each case, fluorescent PCR was performed in duplicate using undigested and digested DNA; the products were resolved by capillary electrophoresis with an ABI Prism 310 Sequencer and analyzed using GeneScan software. XCI values were calculated in heterozygotes as reported by Sharp et $a l^{29}$ Skewing was defined as an XCI ratio of 75:25 or more. ${ }^{29}$

The segregation analysis of the $A R$ polymorphic locus from parents to fetus allows to detect the parental origin of the $\mathrm{X}$ chromosomes, and therefore alterations in the segregation pattern, such as uniparental disomy (UPD) and $\mathrm{X}$ aneuploidy.

\section{ESX1L expression study}

After washing and microscopic inspection, the chorionic villi were immediately submerged and stored in RNAlater ${ }^{\mathrm{TM}}$ (Ambion, Austin, USA), a solution that rapidly stabilizes and protects cellular RNA in unfrozen specimens. After an overnight incubation at $4^{\circ} \mathrm{C}$, samples were transferred to $-20^{\circ} \mathrm{C}$ till the time of RNA extraction with Trizol (Invitrogen, Carlsbad, CA, USA).

A measure of $200 \mathrm{ng}$ of DNase-treated total RNA was amplified using the Superscript One-Step RT-PCR System (Life Technologies) with ESX1L primers: exon 3 sense primer 5'-CAG CAC GCC TGA ATT TGA CT-3' and exon 4 antisense primer 5'-GTA GTT GTG GCA CCA GAT GA-3'. Amplification was carried out for 30 cycles at an annealing temperature of $53^{\circ} \mathrm{C}$.

The RNA integrity and the efficiency of the reverse transcription were monitored by amplification of hypoxantine phosphoribosyltransferase (HPRT) (sense primer 5'-GTT GAG AGA TCA TCT CCA CC-3' and antisense primer 5'-AGC TAT GAT GAA CCA GGT TA-3'). 
Table 2 PCR primers used for MSP

\begin{tabular}{lllrr}
\hline Primer set & \multicolumn{1}{c}{ Sense primer, $5^{\prime} \rightarrow 3^{\prime}$} & \multicolumn{1}{c}{ Antisense primer, $5^{\prime} \rightarrow 3^{\prime}$} & Size $(\mathrm{bp})$ & Annealing temp. $\left({ }^{\circ} \mathrm{C}\right)$ \\
\hline ESX1L-WT & GGATCGCCGCGGAACCAC & GTTGGAGCCCACGGCGCG & 302 & 58 \\
ESX1L-M & ATTTCGGGATCGTCGCGGAATTAC & AAACGTTAAAACCCACGACGCG & 312 & 55 \\
ESX1L-U & ATTTTGGGATTGTTGTGGAATTAT & AAAACATTAAAACCCACAACACA & 313 & 50 \\
\hline
\end{tabular}

Sequence differences between modified primers and unmodified DNA are in boldface and differences between methylated/modified and unmethylated/modified are underlined.

Primers were placed near the ATG sequences, Genbank accession number 4938307.

WT represents unmodified primers, $M$ methylated-specific primers and $U$ unmethylated-specific primers.

Table 3 Cytogenetic and molecular results

\begin{tabular}{|c|c|c|c|c|c|c|c|c|c|}
\hline \multirow[t]{3}{*}{ CASE/fetal karyotype } & \multirow{2}{*}{\multicolumn{3}{|c|}{ AR alleles }} & \multicolumn{6}{|c|}{ XCI VALUES } \\
\hline & & & & \multicolumn{2}{|c|}{ Fetal DNAs } & \multicolumn{4}{|c|}{ Placental DNAs } \\
\hline & $M$ & $F$ & $P$ & UC & $C B$ & $A$ & $B$ & C & $D$ \\
\hline $3(46, X X)$ & 1,2 & 2,3 & 3 & $45: 55(\mathrm{R})$ & - & $25: 75\left(X^{P}\right)$ & $30: 70(\mathrm{R})$ & $36: 64(\mathrm{R})$ & $45: 55(\mathrm{R})$ \\
\hline $8(46, X X)$ & 2,3 & 1,3 & 1 & - & $50: 50(R)$ & $78: 22\left(X^{P}\right)$ & $99: 1\left(X^{P}\right)$ & $99: 1\left(X^{P}\right)$ & $36: 64(\mathrm{R})$ \\
\hline $9(46, X X)$ & 1,2 & 1,1 & 1 & - & $\mathrm{NI}$ & $\mathrm{NI}$ & & & \\
\hline $12(46, X X)$ & 2,3 & 1,2 & 1 & - & $37: 63(\mathrm{R})$ & $11: 89\left(\mathrm{X}^{\mathrm{M}}\right)$ & $43: 57(\mathrm{R})$ & $21: 79\left(\mathrm{X}^{\mathrm{M}}\right)$ & - \\
\hline $13(46, X X)$ & 1,2 & 1,3 & 3 & $50: 50(R)$ & - & $53: 47(\mathrm{R})$ & $90: 10\left(X^{M}\right)$ & $15: 85\left(X^{P}\right)^{\prime}$ & - \\
\hline $15(46, X X)$ & 1,1 & 1,2 & 2 & $52: 48(\mathrm{R})$ & $70: 30(\mathrm{R})$ & $65: 35(\mathrm{R})$ & $16: 84\left(X^{P}\right)^{\prime}$ & $81: 19\left(X^{M}\right)$ & $13: 87\left(X^{P}\right)$ \\
\hline $20(46, X X)$ & 1,2 & 1,3 & 3 & $48: 52(\mathrm{R})$ & $56: 44(\mathrm{R})$ & $15: 85\left(X^{P}\right)$ & $16: 84\left(X^{P}\right)$ & $23: 77\left(X^{P}\right)^{\prime}$ & $75: 25\left(X^{M}\right)$ \\
\hline $30(46, X X)$ & 1,3 & 1,2 & 2 & $40: 60(\mathrm{R})$ & - & $41: 59(\mathrm{R})$ & - & $25: 75\left(X^{P}\right)$ & - \\
\hline $33(46, X X)$ & 1,2 & 1,3 & 3 & $85: 15\left(X^{M}\right)$ & $83: 17\left(X^{M}\right)$ & $75: 25\left(X^{M}\right)$ & $86: 14\left(X^{M}\right)$ & - & $92: 8\left(X^{M}\right)$ \\
\hline $35(47, X X X)$ & 1,2 & $1,2,3$ & 3 & - & $X^{\mathrm{M} 1} X^{\mathrm{P}}$ & $x^{\mathrm{M} 2} x^{\mathrm{P}}$ & $X^{M 1} X^{P}$ & - & $\mathrm{X}^{\mathrm{M} 1} \mathrm{X}^{\mathrm{M} 2}$ \\
\hline $36(46, X X)$ & 2,3 & 1,3 & 1 & - & $39: 61(R)$ & $12: 88\left(X^{M}\right)$ & - & $25: 75\left(X^{M}\right)$ & $31: 69(\mathrm{R})$ \\
\hline $37(46, X X)$ & 2,3 & 1,2 & 1 & - & $56: 44(\mathrm{R})$ & $42: 58(\mathrm{R})$ & $88: 12\left(X^{P}\right)$ & $10: 90\left(X^{M}\right)$ & - \\
\hline $40(46, X X)$ & 1,2 & 1,1 & 1 & $\mathrm{NI}$ & $\mathrm{NI}$ & & & & \\
\hline $52(46, X X)$ & 1,3 & 1,2 & 2 & - & $58: 42(\mathrm{R})$ & $50: 50(\mathrm{R})$ & $35: 65(\mathrm{R})$ & $44: 56(\mathrm{R})$ & - \\
\hline $60(46, X X)$ & 1,1 & 1,2 & 2 & - & $50: 50(R)$ & $32: 68(\mathrm{R})$ & $80: 20\left(X^{M}\right)$ & $63: 37(\mathrm{R})$ & - \\
\hline
\end{tabular}

AR alleles of: $M=$ mother; $F=$ fetus; $P=$ father. $U C=$ umbilical cord fragment; $C B=$ cord blood sample; $A-B-C-D=$ placental fragments; $R=$ random $\mathrm{XCl} ; \mathrm{X}^{\mathrm{M}}=$ preferential inactivation of maternally derived $\mathrm{X} ; \mathrm{X}^{\mathrm{P}}=$ preferential inactivation of paternally derived $\mathrm{X} ; \mathrm{NI}=$ not informative; $-=$ not analyzed.

\section{ESX1L methylation-specific PCR}

Bisulfite modification of genomic DNA was essentially performed as described by Herman et al. ${ }^{30}$ Modified DNA was used immediately or stored in aliquots at $-20^{\circ} \mathrm{C}$.

The PCR mixture contained $1 \times$ PCR buffer $(10 \mathrm{~mm}$ Tris$\mathrm{HCl}, 50 \mathrm{~mm} \mathrm{KCl}, 0.1 \%$ Triton $\mathrm{X}-100$ and $1.5 \mathrm{~mm} \mathrm{MgCl}_{2}$ ), dNTPs (each at $1.25 \mathrm{~mm}$ ), primers (300 ng each per reaction) and bisulfite-modified DNA (100 ng). Reactions were hot started at $95^{\circ} \mathrm{C}$ before the addition of $2.5 \mathrm{U}$ of Taq polymerase (Promega). Amplification was carried out for 30 cycles $\left(1 \mathrm{~min}\right.$ at $94^{\circ} \mathrm{C}, 1 \mathrm{~min}$ at the annealing temperature selected for each primer pair (Table 1), and $1 \mathrm{~min}$ at $72^{\circ} \mathrm{C}$ ), followed by $5 \mathrm{~min}$ at $72^{\circ} \mathrm{C}$. In all, $12 \mu \mathrm{l}$ of the PCR reaction was electrophoresed onto $2 \%$ agarose gels, stained with ethidium bromide, and visualized under UV. The methylation-specific PCR (MSP) primers, described in Table 2, were designed on the human EXS1L CpG island (gi 4938307).

\section{Results}

\section{Cytogenetic and XCI studies}

Cytogenetic analysis of the placental specimens and $\mathrm{CB}$ lymphocytes revealed a normal karyotype in all except in case 35 , which showed a 47,XXX karyotype.
The XCI values are reported in Table 3. Of 13 IUGR fetuses, 11 were informative at AR locus. In placental samples, a heterogeneous XCI pattern varying from random to preferential $\mathrm{XCI}\left(\mathrm{X}^{\mathrm{P}}\right.$ or $\left.\mathrm{X}^{\mathrm{M}}\right)$ was found in $9 / 10$ euploid cases: the only exception was case 33 , in which the $\mathrm{X}^{\mathrm{M}}$ was preferentially inactivated in all of the placental and fetal samples. Considering $3346, \mathrm{XX}$ cotyledons, 10 (30.3\%) showed random XCI, $11(33.3 \%)$ preferential $\mathrm{X}^{\mathrm{M}}$ inactivation and $12(36.4 \%)$ preferential $\mathrm{X}^{\mathrm{P}}$ inactivation. An example of a heterogeneous XCI pattern (case 37) is depicted in Figure 1, in which cotyledon A shows random $\mathrm{XCI}, \mathrm{B}$ a preferential $\mathrm{X}^{\mathrm{P}}$ inactivation and $\mathrm{C}$ a preferential $\mathrm{X}^{\mathrm{M}}$ inactivation. In case $35, A R$ allele segregation showed that the trisomy $\mathrm{X}$ was of maternal origin (Table 3 ) and the XCI pattern of placental cotyledons was heterogeneous with inactivation of both $\mathrm{X}^{\mathrm{M}}$ or $\mathrm{X}^{\mathrm{M}}$ and $\mathrm{X}^{\mathrm{P}}$ (Figure 1).

The XCI patterns in fetal samples (UC and CB) were random in all informative cases, except case 33. In cases 33 and 35 (data not shown), the AR assay was also extended to maternal DNA and showed a random and a preferential (87:13) XCI pattern, respectively.

$\mathrm{XCI}$ analysis was also performed in the two female controls (cases 52 and 60) and the results are reported in 
a

\section{Case 37}

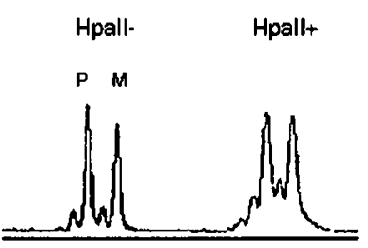

Case 35
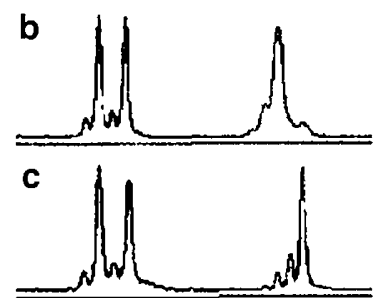

HpallMi Me $P$
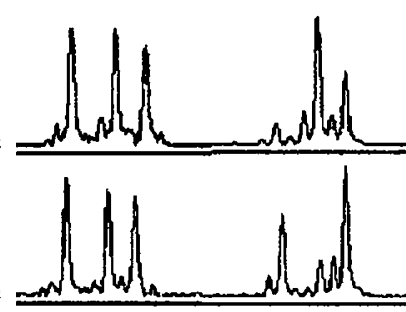

Hpall+

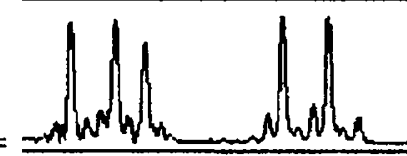

\section{Case 60}
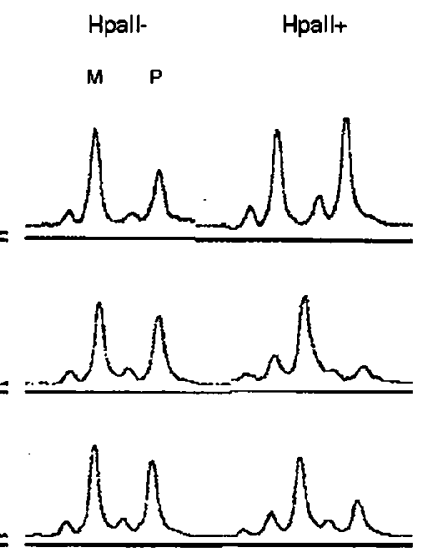

Figure $1 \mathrm{XCl}$ patterns of placental cotyledons from cases 35, 37 and 60 . Case $37(46, X X)$ displays random (cotyledon $A)$ and preferential $X C l$ (cotyledons $B$ and $C$ ); in case $35(47, X X X)$, two of the three alleles are inactivated in different combinations; in case $60(46, X X)$, two cotyledons $\left(A\right.$ and $C$ ) are randomly inactivated and cotyledon $B$ shows preferential $X^{M}$ inactivation. $M$, M1 and M2: maternal alleles; P: paternal alleles.

Table 3; in Figure 1, the X inactivation patterns of case 60 are depicted.

Segregation analysis revealed the biparental origin of the $\mathrm{X}$ chromosomes in all cases, thus excluding UPD of chromosome $\mathrm{X}$ in all euploid cases.

Histological examination of the sampled placental cotyledons did not reveal any apparent correlation with the different XCI patterns in terms of the prevailing ramification pattern or villous maturation (data not shown).

IUGR severity did not correlate with the XCI patterns, and the most severe IUGR cases were not associated with prevalent $\mathrm{X}^{\mathrm{M}}$ inactivation.

\section{ESX1L RT-PCR analysis}

We analyzed RNAs from two male and two female normal full-term placentas, four placental cotyledons randomly inactivated $(12 \mathrm{~B}, 15 \mathrm{~A}, 30 \mathrm{~A}$ and $36 \mathrm{D})$, four placental cotyledons showing preferential $\mathrm{X}^{\mathrm{P}}$ inactivation $(8 \mathrm{~B}, 8 \mathrm{C}$, $15 \mathrm{D}$ and 37B) and eight placental cotyledons with preferential $\mathrm{X}^{\mathrm{M}}$ inactivation $(12 \mathrm{~A}, 12 \mathrm{C}, 13 \mathrm{~B}, 33 \mathrm{~A}, 33 \mathrm{~B}$, $33 \mathrm{D}, 36 \mathrm{~A}$ and $37 \mathrm{C})$. Of these latter cases, case 33 showed complete $\mathrm{X}^{\mathrm{M}}$ skewing in all placental and fetal samples.

ESX1L was expressed in all placental fragments analyzed and the band intensity did not differ among samples. Figure 2 presents the results of one male, one female normal placentas and one placental sample for each XCI status (random, $\mathrm{X}^{\mathrm{P}}$ and $\mathrm{X}^{\mathrm{M}}$ ). Testis and a breast tumor cell line (MDA-MB-231) RNAs were used as positive ${ }^{23}$ and negative controls, respectively.

\section{ESX1L methylation analysis}

The samples described for RT-PCR were also analyzed by means of MSP. The ESX1L promoter methylation status was

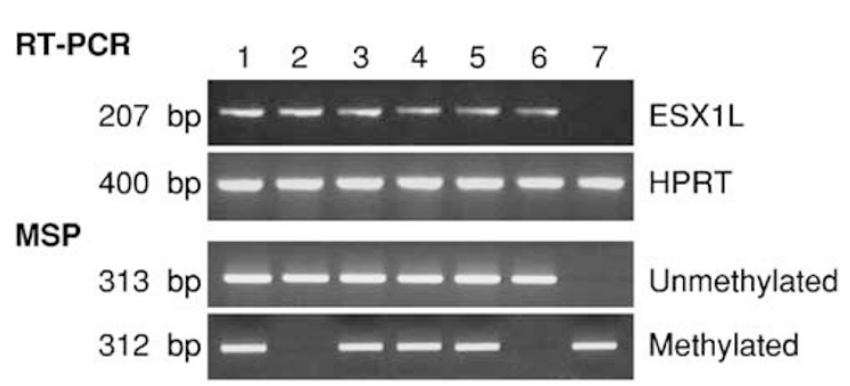

Figure 2 ESX1L expression and methylation status. Lane 1: normal full-term female placenta; lane 2: normal fullterm male placenta; lane 3: cotyledon 33A (preferential $X^{M}$ inactivation); lane 4: cotyledon $8 C$ (preferential $X^{P}$ inactivation); lane 5: cotyledon $36 \mathrm{D}$ (random inactivation); lane 6: testis; and lane 7: MDA-MB-231 breast cancer cell line.

different between male and female samples. Female placentas showed one methylated and one unmethylated alleles, while male placentas as well as testis was unmethylated, as expected by chromosome $\mathrm{X}$ number. Female placental fragments displayed the same MSP pattern in cotyledons with $\mathrm{X}^{\mathrm{M}}$ or $\mathrm{X}^{\mathrm{P}}$ preferentially inactivated. The MDA-MB-231 cell line was positive only for the methylated-specific primers. The RT-PCR results were completely in accordance with the methylation status of the gene. Figure 2 also reports MSP results of the samples tested for RT-PCR.

\section{Discussion}

The $\mathrm{X}^{\mathrm{P}}$ in murine placenta is imprinted and always undergoes inactivation, probably because of the existence of imprinted genes, such as Esx1, expressed on $\mathrm{X}^{\mathrm{M}}$ during placental development. Mutant Esx1 mice are 20\% smaller 
because of placental insufficiency; Li and Behringer ${ }^{22}$ and Looijenga et $\mathrm{al}^{7}$ have suggested that this gene may be implicated in the pathogenesis of human IUGR, although the imprinting status of the human ESX1L has not yet been demonstrated. ${ }^{23}$

We studied the XCI pattern and ESX1L placental expression of placental tissues from 13 female IUGR pregnancies in order to investigate a possible parent-oforigin effect of chromosome $\mathrm{X}$ in IUGR placentas. A heterogeneous XCI pattern (varying from random to preferential) was observed in 10/11 IUGR informative cases and in the two controls. All the euploid cases had a normal $\mathrm{X}$ chromosome inheritance pattern, thus excluding UPD in our cohort of IUGR. Similar percentages of random, preferential $\mathrm{X}^{\mathrm{P}}$ and preferential $\mathrm{X}^{\mathrm{M}}$ inactivation were found in the 33 diploid IUGR placental specimens, although there was a trend toward preferential $\mathrm{X}^{\mathrm{P}}$ inactivation. These findings are similar to those previously reported in normal full-term placentas and first-trimester chorionic villi, ${ }^{7-9}$ and indicate that, in the studied cases, IUGR was not associated with a specific XCI pattern.

In case $35(47, \mathrm{XXX}), A R$ analysis from parents to daughter showed that a meiotic maternal nondisjunction error occurred. The three placental samples had a heterogeneous XCI pattern, with either $\mathrm{X}^{\mathrm{P}}$ or $\mathrm{X}^{\mathrm{M}}$ being inactivated. To our knowledge, this is the first XCI evaluation of a placenta with $47, \mathrm{XXX}$ karyotype. In this case, the AR assay was extended to the mother's DNA, which showed XCI skewing. It has been reported that women with recurrent spontaneous abortions caused by aneuploidy frequently show skewed inactivation. These women are probably carriers of a germ-line occult aneuploid cell line, which means that they were probably derived from an aneuploid conceptus 'normalized' by a chromosome loss at an early postzygotic stage. After aneuploidy rescue, the residual abnormal cells are negatively selected, thus leading to a reduction in the number of early embryonic precursor cells and germ-line mosaicism. ${ }^{31-34}$ In mice, but not in humans, the presence of an additional X chromosome of maternal origin leads to severe IUGR or early abnormal development characterized by deficient extraembryonic structure. ${ }^{14}$ We cannot exclude the possibility that, in our case, there was a relationship between the trisomy $\mathrm{X}$ of maternal origin and IUGR, although no evidence of such a possibility has been previously reported.

Case $33(46, \mathrm{XX})$ showed preferential XCI of the $\mathrm{X}^{\mathrm{M}}$ in all of the analyzed samples; the mother had a random XCI pattern. We hypothesize that the skewing was due to a de novo X-linked gene mutation or an undetected chromosomal mosaicism.
The histological findings in the sampled placental cotyledons did not correlate with the different XCI patterns in terms of the prevailing ramification or villous maturation.

There was also no correlation between the XCI pattern and the severity of IUGR, and case 33 did not show very severe IUGR, despite being characterized by strongly preferential $\mathrm{X}^{\mathrm{M}}$ inactivation.

RT-PCR analysis confirmed that ESX1L was expressed in normal full-term placenta, as previously reported by Fohn and Behringer, ${ }^{23}$ as well as in IUGR placental cotyledons showing different kinds of XCI patterns. No differences in signal intensities were displayed among those with prevalent $\mathrm{X}^{\mathrm{M}}$, prevalent $\mathrm{X}^{\mathrm{P}}$ and random inactivation. These data indicate that the XCI pattern does not affect the ESX1L expression and the gene is active also in the presence of a generalized skewing of chromosome $\mathrm{X}^{\mathrm{M}}$.

Due to the lack of SNPs within the coding region, the allele-specific RT-PCR technique was not performed; to evaluate ESX1L imprinting status in human placenta, we studied the methylation pattern of the ESX1L CpG island. As expected from RT-PCR ESX1L results on placental RNAs, both methylated and unmethylated alleles were found in female placentas, with $\mathrm{X}^{\mathrm{M}}$ or $\mathrm{X}^{\mathrm{P}}$ preferentially inactivated. These findings indicate that the ESX1L gene is not imprinted in third-trimester placentas. Nevertheless, gene sequencing and protein analysis are necessary to draw the conclusion that the ESX1L gene is not involved in IUGR. Discrepancy of the imprinting status of loci between humans and mice has already been reported for $I g f 2 R / I G F 2 R$; in an extensive study of seven placentas, 46 conceptuses and seven Wilm's tumors, Killian et $a l^{35}$ found no evidence of imprinting of IGF2R in humans.

Taken together, our findings, which are strengthened by the absence of clinical manifestations attributable to imprinting in females carrying UPD $\mathrm{X},{ }^{32,33}$ support the exclusion of the involvement of putative imprinted $\mathrm{X}$-linked genes related to fetal growth. Other authors ${ }^{36,37}$ have hypothesized that $X$ imprinting in humans may contribute to the development of social cognitive skills, as demonstrated in Turner's syndrome; otherwise, in mouse, $\mathrm{X}$ imprinting affects early development and growth.

On the basis of our results, we conclude that there is no parent-of-origin effect of chromosome $\mathrm{X}$ associated with the IUGR phenotype.

\section{Acknowledgements}

This work was supported by a grant from the ASM onlus (Associazione Italiana Studio Malformazioni). Dr FR Grati is a PhD student in Human Pathology at the University of Pavia, Italy. 


\section{References}

1 Lyon MF: Gene action in the X chromosome of the mouse (Mus musculus L. Nature 1961; 190: 372-373.

2 Carrel L, Cottle AA, Goglin KC, Willard HF: A first-generation $\mathrm{X}$-inactivation profile of the human X chromosome. Proc Natl Acad Sci USA 1999; 96: 14440-14444.

3 Tan SS, Williams EA, Tam PP: X-chromosome inactivation occurs at different times in different tissues of the post-implantation mouse embryo. Nat Genet 1993; 3: 170-174.

4 Lanasa MC, Hogge WA, Kubik C, Blancato J, Hoffman EP: Highly skewed $\mathrm{X}$-chromosome inactivation is associated with idiopathic recurrent spontaneous abortion. Am J Hum Genet 1999; 65: 252-254.

5 Brown CJ, Robinson WP: The causes and consequences of random and non-random $\mathrm{X}$ chromosome inactivation in humans. Clin Genet 2000; 58: 353-563.

6 Goto T, Wright E, Monk M: Paternal X-chromosome inactivation in human trophoblastic cells. Mol Hum Reprod 1997; 3: 77-80.

7 Looijenga LH, Gillis AJ, Verkerk AJ, van Putten WL, Oosterhuis JW: Heterogeneous $\mathrm{X}$ inactivation in trophoblastic cells of human full-term female placentas. Am J Hum Genet 1999; 64: $1445-1452$.

8 Uehara S, Tamura M, Nata M et al:: X-chromosome inactivation in the human trophoblast of early pregnancy. J Hum Genet 2000; 45: 119-126.

9 Zeng SM, Yankowitz J: X-inactivation patterns in human embryonic and extra-embryonic tissues. Placenta 2003; 24: $270-275$.

10 Marahrens Y, Panning B, Dausman J, Strauss W, Jaenisch: Xistdeficient mice are defective in dosage compensation but not spermatogenesis. Genes Dev 1997; 11: 156-166.

11 Avner P, Heard E: X-chromosome inactivation: counting, choice and initiation. Nat Rev Genet 2001; 2: 59-67.

12 Shao C, Takagi N: An extra maternally derived X chromosome is deleterious to early mouse development. Development 1990; 110: 969-975.

13 Takagi N, Abe K: Detrimental effects of two active X chromosomes on early mouse development. Development 1990; 109: 189-201.

14 Tada T, Takagi N, Adler ID: Parental imprinting on the mouse X chromosome: effects on the early development of X0, XXY and XXX embryos. Genet Res 1993; 62: 139-148.

15 Goto Y, Takagi N: Maternally inherited X chromosome is not inactivated in mouse blastocysts due to parental imprinting. Chromosome Res 2000; 8: 101-109.

16 Pardi G, Marconi AM, Cetin I: Interrelationship in IUGR fetuses: a review. Placenta 2002; 23: S136-41.

17 Resnik R: Intrauterine growth restriction. Obstet Gynecol 2002; 99: 490-496.

18 Constancia M, Hemberger M, Hughes J et al:: Placental-specific IGF-II is a major modulator of placental and fetal growth. Nature 2002; 417: 945-948.

19 Miozzo M, Simoni G: The role of imprinted genes in fetal growth. Biol Neonate 2002; 81: 217-228.

20 Reik W, Constancia M, Fowden A et al:: Regulation of supply and demand for maternal nutrients in mammals by imprinted genes. J Physiol 2003; 547: 35-44.
21 Li Y, Lemaire P, Behringer RR: Esx1, a novel X chromosomelinked homeobox gene expressed in mouse extraembryonic tissues and male germ cells. Dev Biol 1997; 188: 85-95.

22 Li Y, Behringer RR: Esx1 is an X-chromosome-imprinted regulator of placental development and fetal growth. Nat Genet 1998; 20: 309-311.

23 Fohn LE, Behringer RR: ESX1L: a novel X chromosome-linked human homeobox gene expressed in the placenta and testis. Genomics 2001; 74: 105-108.

24 Todros T, Ferrazzi E, Groli C et al:: Fitting growth curves to head and abdomen measurements of the fetus: a multicentric study. J Clin Ultrasound 1987; 15: 95-105.

25 Parazzini F, Cortinovis I, Bortolus R, Fedele L: Standard di peso alla nascita in Italia. Ann Ost Gin Med Perin 1991; CXII: 203-246.

26 Pardi G, Cetin I, Marconi A et al:: Diagnostic value of blood sampling in fetuses with growth retardation. N Engl J Med 1993; 328: $692-696$.

27 Benirschke K, Kaufmann P: Classification of villous maldevelopment. in Pathology of the Human Placenta. Springer Verlag, N.Y.Inc., 2000, 4 th edn, pp 440-458.

28 Allen RC, Zoghbi HY, Moseley AB, Rosenblatt HM, Belmont JW: Methylation of HpaII and HhaI sites near the polymorphic CAG repeat in the human androgen-receptor gene correlates with X chromosome inactivation. Am J Hum Genet 1992; 51: 1229-1239.

29 Sharp A, Robinson D, Jacobs P: Age- and tissue-specific variation of $\mathrm{X}$ chromosome inactivation ratios in normal women. Hum Genet 2000; 107: 343-349.

30 Herman JG, Graff JR, Myohanen S, Nelkin BD, Baylin SB: Methylation-specific PCR: a novel PCR assay for methylation status of CpG islands. Proc Natl Acad Sci USA 1996; 93: 9821-9826.

31 Lau AW, Brown CJ, Penaherrera M, Langlois S, Kalousek DK, Robinson WP: Skewed X-chromosome inactivation is common in fetuses or newborns associated with confined placental mosaicism. Am J Hum Genet 1997; 61: 1353-1561.

32 Stavropoulos DJ, Bick D, Kalousek DK: Molecular cytogenetic detection of confined gonadal mosaicism in a conceptus with trisomy 16 placental mosaicism. Am J Hum Genet 1998; 63: $1912-1914$.

33 Penaherrera MS, Barrett IJ, Brown CJ et al:: An association between skewed X-chromosome inactivation and abnormal outcome in mosaic trisomy 16 confined predominantly to the placenta. Clin Genet 2000; 58: 436-446.

34 Beever CL, Stephenson MD, Penaherrera MS et al:: Skewed $\mathrm{X}$-chromosome inactivation is associated with trisomy in women ascertained on the basis of recurrent spontaneous abortion or chromosomally abnormal pregnancies. Am J Hum Genet 2003; 72: 399-407.

35 Killian JK, Nolan CM, Wylie AA et al:: Divergent evolution in M6P/IGF2R imprinting from the Jurassic to the Quaternary. Hum Mol Genet 2001; 10: 1721-1728.

36 Skuse DH, James RS, Bishop DV et al:: Evidence from Turner's syndrome of an imprinted X-linked locus affecting cognitive function. Nature 1997; 387: 705-708.

37 Iwasa Y, Pomiankowski A: The evolution of X-linked genomic imprinting. Genetics 2001; 158: 1801-1809. 